\title{
The Synthesis and Release of Insulin in Fetal, Nursing and Young Adult Rats: Studies in Vivo and in Vitro
}

\author{
ENRIQUE BLÁZQUEZ, LEON A. LIPSHAW, MERCEDES BLÁZQUEZ, AND PIERO P. FOA ${ }^{(83)}$
}

Department of Research, Sinai Hospital of Detroit, Detroit, Michigan, USA

\section{Extract}

The secretion of insulin in vivo and its synthesis and release by pancreatic islets in vitro were studied in rats at various stages of development. An oral glucose load caused a rapid and significant increase in the serum insulin level of pregnant rats and a slower response in their 21-day-old fetuses. Circulating free fatty acids (FFA) decreased in the dams, but did not change in the fetuses. A relative glucose intolerance was found in pups $1 \mathrm{hr}, 5$ days, and 10 days after birth. This was accompanied by delayed insulin response and by little or no decrease of circulating FFA. After weaning, the glucose tolerance and the insulin and FFA responses gradually improved. The oral administration of a 10 -amino acid mixture caused a greater insulin release in newborn and nursing rats than in 21-day-old fetuses or in young adult rats. Total serum lipids were higher in 1-, 5-, 10-, and 20-day-old rats than in fetuses and adult animals, whether fed or fasted, but $18 \mathrm{hr}$ of fasting decreased total lipids and phospholipids in all age groups. Thus, the age of relative hyperlipidemia corresponded with that of relative glucose intolerance. The secretion of insulin in vitro by pancreatic islets of 5-, 10-, 20-, 30-, and 45-day-old rats increased significantly when the concentration of glucose in the incubation medium was increased from 30 to $300 \mathrm{mg} / \mathrm{ml}$. The islets of 30 - and 45 -day-old rats secreted the largest amount of insulin. The insulin content of pancreatic islets was higher and the percentage of insulin secreted in relation to the hormonal content was smaller in the islets of nursing rats. Islets of fetal, nursing, and adult rats incorporated $\mathrm{L}-\left[4,5-{ }^{3} \mathrm{H}\right]$ leucine into proinsulin and insulin, but the conversion of proinsulin to insulin was minimal in the 1-day-old rat. This incorporation was greater when the glucose concentration of the medium or the incubation time were increased. Thus, birth appears to be associated with a temporary decrease in the ability to release insulin and to dispose of an exogenous glucose load.

\section{Speculation}

Birth deprives the newborn pup of transplacental nutrition and exposes it to the danger of neonatal hypoglycemia, especially in the interval between birth and the first act of nursing. This danger is moderated by a previously described increase in the serum level of glucagon and by a decrease in the serum level of insulin. This change in the glucagon to insulin ratio favors hepatic glycogenolysis and gluconeogenesis and, possibly aided by the relative hyperlipidemia characteristic of this age, decreases the utilization of glucose by the relatively large masses of insulin-responsive tissues. Gluconeogenesis continues to be a major source of glucose throughout the nursing age, when the animal consumes a diet rich in protein and fat and low in carbohydrate. Although the fetal pancreas can synthesize insulin, the mechanism for its release and hence the ability to dispose of a glucose load do not reach full maturity until weaning, when the dietary intake of carbohydrate increases and the level of serum lipids decreases toward the values characteristic of the adult animal.

The synthesis and storage of insulin in the pancreatic B cells of the rat appear to start during the 11th day of gestation (36, 59). However, the precise time at which the insulin-releasing mechanism begins to function has not been determined and may vary with the nature of the stimulus. Thus, the fetal pancreas, even though insensitive to glucose $(4,50)$, may respond to other substances (see Reference 37 ) so that, toward the end of pregnancy, the fetal serum insulin (IRI) reaches values that are higher than those found in the dam $(2,13,26$, $42,63)$. A significant decrease in fetal serum IRI occurs on the last day of intrauterine life (14), at the time when the level of glucagon and, consequently, the glucagon to insulin ratio, increase markedly $(14,15,31)$, possibly explaining why the mammalian neonate does not tolerate a glucose load as well as the adult animal $(49,64)$. The experiments described in this paper were designed to study the relative importance of insulin synthesis and of insulin release in this perinatal change. For this purpose we studied the effects of an oral glucose or amino acid load in the pregnant rat and in her fetuses and in newborn, nursing, and weaning rats and we attempted to correlate the results of these experiments in vivo with the results obtained in vitro, using pancreatic islets isolated from comparable groups of animals. This paper will provide evidence that significant changes in the rate of hormone synthesis did not occur during this period of the life of the rat and, therefore, could not have been the cause of the observed changes in the rate of insulin release and of glucose utilization.

\section{MATERIALS AND METHODS}

\section{ANIMALS}

Female Wistar rats, weighing $200-250 \mathrm{~g}$, with free access to food (Purina chow) and water, were caged with males until mating had occurred. This was ascertained by examining the vaginal smear every day between 8 and 9 AM; the day when spermatozoa were found was considered the first day of 
pregnancy. Since rats, generally, copulate during the night and since ovulation occurs at about 2 AM (24), the duration of pregnancy was estimated with a possible error of 6-12 hours. The animals did, in fact, deliver on the anticipated 22 nd day after mating. On that day, they were kept under observation and the actual time of birth was noted for each pup. Young rats were killed at the age of $1 \mathrm{hr}, 5,10,20,30$, and 45 days. When indicated, fetuses were removed by cesarean section immediately after the dam had been killed by cervical dislocation. As soon as possible thereafter, as one of us was drawing maternal blood from the inferior vena cava, another collected fetal blood by decapitation.

\section{IN VIVO EXPERIMENTS}

Oral Administration of Glucose and of Amino Acids. Dams on the 21 st day of pregnancy and 1-hr, 5-, 10-, 20-, 30-, and 45 -day-old offspring were given glucose $(2 \mathrm{~g} / \mathrm{kg})$ or a 10 -amino acid mixture $(1 \mathrm{~g} / \mathrm{kg} ;(27))$ by means of a gastric polyethylene catheter of a diameter suitable to the size of the animal. All animals except the 1-hr-old pups were fasted overnight. Neonatal and nursing rats were kept in a moist incubator at $37^{\circ}$, a precaution used also by other workers (31) and designed to create conditions similar to those of the nest. All animals were killed at different times after the load, bled, and their abdominal cavity was opened to make sure that the fluid had been placed into the stomach. The blood samples were collected in prechilled test tubes, allowed to clot, centrifuged at $4^{\circ}$; the sera were frozen and preserved at $-20^{\circ}$ for subsequent analysis. Glucose was determined enzymatically (44); FFA photometrically (18), and IRI with a double antibody immunoassay (39), using a rat insulin standard (73). Serum lipids were extracted from $0.2 \mathrm{ml}$ serum (28) and, after evaporation of the solvents under a stream of nitrogen, were dissolved in $0.5 \mathrm{ml}$ chloroform-methanol mixture $(2: 1 ; \mathrm{v} / \mathrm{v})$. A $50-\mu$ l aliquot of this solution was transferred to a suitable aluminum pan, evaporated to dryness, and weighed on a Cahn electrobalance. A second $50-\mu 1$ aliquot was used for the determination of lipid phosphorus (6).

\section{IN VITRO EXPERIMENTS}

Preparation of Pancreatic Islets. Immediately after the animals were killed, their pancreases. were removed and cut into small pieces. The fragments were transferred to glass tubes containing Hank's-Wallace buffer (40) and collagenase (74) and shaken at 170 strokes/min for $10 \mathrm{~min}$ at $37^{\circ}$. The number of glands, the amount of collagenase, and the volume of buffer varied according to the age of the rat, as follows: fetal, neonatal, 5- and 10-day-old rats, 6 to 10 pancreases, $2 \mathrm{ml}$ buffer, and $5.0 \mathrm{mg}$ collagenase; 30-day-old animals, 2 pancreases, $2 \mathrm{ml}$ buffer, and $7.0 \mathrm{mg}$ collagenase; 45-day-old animals, 1 pancreas, $6 \mathrm{ml}$ buffer, and $27 \mathrm{mg}$ collagenase. After digestion, enough ice-cold buffer was added to each sample to make a total volume of $30 \mathrm{ml}$ and the samples were centrifuged at low speed. Twenty-five milliliters of supernatant fluid were discarded and the islets were washed again in the same manner, recentrifuged, and picked out of the buffer with the aid of a small wire loop and a dissecting microscope.

Insulin Secretion by Pancreatic Islets. Samples of 10 islets, obtained from 5-, 10-, 30-, and 45-day-old rats, as described above, were transferred to a flask containing $3 \mathrm{ml} \mathrm{Krebs}$ Ringer bicarbonate buffer enriched with albumin $(10 \mathrm{mg} / \mathrm{ml})$ and glucose $(30$ or $300 \mathrm{mg} / 100 \mathrm{ml}$ ) and were placed in a Dubnoff metabolic incubator oscillating at the rate of $66 \mathrm{cpm}$, in an atmosphere of $95 \% \mathrm{O}_{2}$ and $5 \% \mathrm{CO}_{2}$, at $37^{\circ}$. After $2 \mathrm{hr}$ of incubation, the islets were removed by centrifugation at $280 \times g$ for $5 \mathrm{~min}$ and the concentration of IRI in the buffer was measured by radioimmunoassay (53).

Insulin Content of Pancreatic Islets. Similar samples of 10 pancreatic islets were homogenized in $0.1 \mathrm{M}$ phosphate buffer, $\mathrm{pH} 7.4$, containing albumin $(10 \mathrm{mg} / \mathrm{ml})$. Enough trichloroacetic acid (TCA) was added to make a final concentration of $10 \%$. The TCA precipitate was extracted three times with acid alcohol (ethanol, 75; water, 25; concentrated $\mathrm{HCl}, 1.5 \mathrm{v} / \mathrm{v} / \mathrm{v}$ ) at $4^{\circ}$. The three extracts were pooled and aliquots were neutralized to $\mathrm{pH} 7$ with $0.154 \mathrm{M}$ sodium bicarbonate and diluted with $0.1 \mathrm{M}$ phosphate buffer, $\mathrm{pH}$ 7.4, containing albumin $(10 \mathrm{mg} / \mathrm{ml})$, for insulin assay (53).

Synthesis of Proinsulin and Insulin by Pancreatic Islets. Other samples of 10 islets each were placed in small glass homogenizers with $0.5 \mathrm{ml}$ Krebs-Ringer bicarbonate buffer containing albumin $(1 \mathrm{mg} / \mathrm{ml})$, glucose $(100,200$, or 300 $\mathrm{mg} / \mathrm{ml})$, and $\mathrm{L}-\left[4,5-{ }^{3} \mathrm{H}\right]$ leucine $(30-50 \mathrm{Ci} / \mathrm{mmol}, 10 \mu \mathrm{Ci} / \mathrm{ml}$ (60)) and were incubated for $1,2,3,4$, or $5 \mathrm{hr}$, under the conditions described above. At the end of the incubation, 1 $\mathrm{mg}$ porcine insulin (76), $1 \mathrm{mg}$ albumin, and $1 \mathrm{mg}$ unlabeled L-leucine were added and the islets were homogenized with the medium in which they had been incubated. Proinsulin and insulin were extracted (21) and separated using a column (1 by $60 \mathrm{~cm}$ ) of Sephadex G-50 superfine that had been equilibrated and calibrated with dextran blue, albumin, and with unlabeled and ${ }^{131} \mathrm{I}$-labeled insulin and proinsulin, iodinated using the procedure of Hunter and Greenwood (45). The columns were eluted with $1 \mathrm{M}$ acetic acid, 1-ml fractions were collected, their absorbance was measured at $275 \mathrm{~nm}$, and $0.5-\mathrm{ml}$ aliquots were mixed with $10 \mathrm{ml}$ Bray's solution (16) for the measurement of radioactivity. In some experiments, 0.2 aliquot of the fractions corresponding to the position of proinsulin were taken for the measurement of radioactivity and the rest was lyophilized. The lyophilized product was dissolved in $200 \mu \mathrm{l} 0.15 \mathrm{M}$ Tris buffer, $\mathrm{pH} 8.5$, containing 0.5 or $1 \mu \mathrm{g}$ trypsin (77), and was incubated for $30 \mathrm{~min}$ at $37^{\circ}$. After incubation, acetic acid (final concentration, $1 \mathrm{M}$ ), albumin (1 mg), and porcin insulin (1 mg) were added and the sample was applied again to the Sephadex G-50 superfine column. In other experiments 10 islets were incubated, homogenized, and treated with TCA, as described above. The acid alcohol extraction step was omitted and the precipitate was handled in one of the two following manners. In the first procedure, used for the measurement of total leucine incorporation into extractable proinsulin and insulin, the TCA precipitate was dissolved with $10 \mathrm{mM} \mathrm{HCl}$ in $0.9 \% \mathrm{NaCl}$ solution and was treated with enough anti-insulin serum (AIS; 78) to bind twice as much IRI as was present in the extract. The mixture was incubated for $1 \mathrm{hr}$ at $37^{\circ}, 2 \mathrm{ml}$ rabbit anti-guinea pig serum (79) were added, and the mixture was incubated again at $37^{\circ}$ for $2 \mathrm{hr}$. The precipitate, separated by centrifugation, was dissolved in acid alcohol, the solution was neutralized with Hyamine hydroxide, and the radioactivity of the samples was measured by liquid scintillation after adding $10 \mathrm{ml}$ Bray's solution. In the second procedure, used for the measurement of the relative incorporation of label into the proinsulin and insulin fractions, the TCA precipitate was dissolved in $0.5 \mathrm{ml} 1 \mathrm{M}$ acetic acid and the solution was applied to a Sephadex G-50 superfine chromatography column, without the addition of carrier insulin. The columns were eluted with $1 \mathrm{M}$ acetic acid, 1-ml fractions were collected, and $0.2-\mathrm{ml}$ aliquots were used for measurement of radioactivity. The remaining portions of the samples corresponding to the positions of proinsulin and of insulin, respectively, were pooled, lyophilized in order to remove the acetic acid, and redissolved in $200 \mu \mathrm{l} 0.05 \mathrm{M}$ Veronal buffer $\mathrm{pH}$ 8.6. One-half of each sample was incubated for $2 \mathrm{hr}$ at $37^{\circ}$ with anti-insulin serum and one-half without it. After incubation, the samples were applied to Whatman no. $3 \mathrm{MC}$ paper strips and electrophoresis was carried out at $600 \mathrm{~V}$ for $1.5 \mathrm{hr}$. After this, the paper strips were dried, cut at $1-\mathrm{cm}$ intervals, and counted in $10 \mathrm{ml}$ Bray's solution. Unbound proinsulin and insulin remained at the site of application, 
while the AIS-bound hormones migrated toward the anode, as did samples of human serum dyed with bromphenol blue used as markers.

Histologic Studies. Small pieces of pancreatic tissue were fixed in Bouin solution, embedded in paraffin, cut, and stained with phloxine-azure-hematoxylin (54).

\section{RESULTS}

\section{IN VIVO EXPERIMENTS}

The average weights of the 21-day fetuses and of the 1-hr-old pups were 5.4 and $6.4 \mathrm{~g}$, respectively, those of 5-, 10-, $20-, 30-$, and 45-day-old animals were $13.4,25.2,39.6,75.9$, and $144.5 \mathrm{~g}$ and were similar to the weights reported by Asplund (3). Figure 1 shows that there was no significant difference between the glucose tolerance of the pregnant rats and that of their 21-day-old fetuses. The maternal serum IRI level rose rapidly after glucose ingestion, reaching a peak in 15 min and returning to basal values within $2 \mathrm{hr}$. The fetal IRI values were higher than the maternal values at the start of the experiment, rose more slowly and, having reached a peak $30-60 \mathrm{~min}$ after the ingestion of glucose, remained higher than those of the dam for the remainder of the experiment. After the ingestion of glucose the concentration of FFA decreased in the dam as well as in the fetus, but this change was not statistically significant. Figure 2 shows that 1-hr-old rats had a marked intolerance for a glucose load and little or no insulinogenic response. In the 5-day-old rat, glucose tolerance was still impaired and the insulinogenic response, although significant, was relatively slow. As the animal grew older, the tolerance for glucose increased and the insulinogenic response became more prompt until, at the age of 30 days, they became similar to those of the 45-day-old animal. For technical reasons we could not measure serum FFA levels during the test in the 1-hr-old pups, but in all other animals, they decreased as those of glucose and of insulin increased, gradually returning toward the initial values. Figure 3 shows that the ingestion of a mixture of 10 amino acids did not modify significantly the serum glucose concentration in 10-, 20-, 30-, and 45-day-old rats. However, a significant decrease was observed in 21-day-old fetuses and in 1-hr and 5 -day-old animals. The insulinogenic response was marked $1 \mathrm{hr}$ after birth and decreased progressively with age, until it became undetectable in the 30- and 45-day-old animals. Figure 4 shows that the total serum lipids increased significantly at birth and that this increase continued during the nursing period, reaching maximum values at the age of 20 days. At the time of weaning, when the diet changed from milk (high in fats) to Purina rat chow, the circulating lipids decreased, reaching adult levels in the 30-day-old rat. No significant changes in serum phospholipids were noted during development with the exception of a slight decrease at the time of weaning. A 20 -hr fast decreased the concentration of total lipid and of phospholipid in all animals.

\section{IN VITRO EXPERIMENTS}

Insulin Secretion and Insulin Content of Pancreatic Islets. Table 1 shows that an increase in the concentration of glucose in the incubation medium from 30 to $300 \mathrm{mg} / 100 \mathrm{ml}$ produced a significant stimulation of insulin secretion by the pancreatic islets of rats of all ages. This was most marked in preparations from 30- and 45-day-old animals. On the other hand, islets of 5- and 10-day-old animals contained more insulin than those of 30 - and 45-day-old rats. Thus, the amount of insulin released represented $2.8 \%$ and $7.8 \%$ of the total content in the younger rats and $17.8 \%$ and $14.7 \%$ in the older ones.

Synthesis of Proinsulin and of Insulin by Pancreatic Islets. In Figure $5 A$ we can see that, after incubating the islets of 45-day-old rats in a medium containing glucose and labeled leucine for $4 \mathrm{hr}$, three radioactive peaks similar to those described by Steiner and Oyer (66) could be isolated from islet extracts by chromatography. Peak $I$ represents the void volume of the column and contains the albumin added after incubation; peak $I I$ corresponds to the position of proinsulin, and peak III to the position of insulin. When the material in peak $I I$ was treated with trypsin (Fig. $5 B$ ), it migrated to the position of peak III, eluting with the unlabeled insulin added as a carrier. Upon incubation with guinea pig anti-insulin serum, the materials of peak $I I$ and of peak $I I I$ were bound by the antibody and, accordingly, they migrated toward the anode in the electrophoretic field. The incorporation of labeled leucine into peaks $I I$ and $I I I$ increased significantly when the glucose concentration in the incubation medium was increased (Fig. 5D). The total leucine radioactivity incorporated into proinsulin and insulin by 10 islets of 45 -day-old rats in three different experiments was $6,347,4,897$, and 3,103 cpm. Figure 6 shows that its distribution between the two fractions varied depending upon the age of the animal. Thus, the islets of 21- and 22-day-old fetal rats incorporated significant amounts of leucine into proinsulin and insulin (Fig. $6 A)$, whereas, immediately after birth, the synthesis of
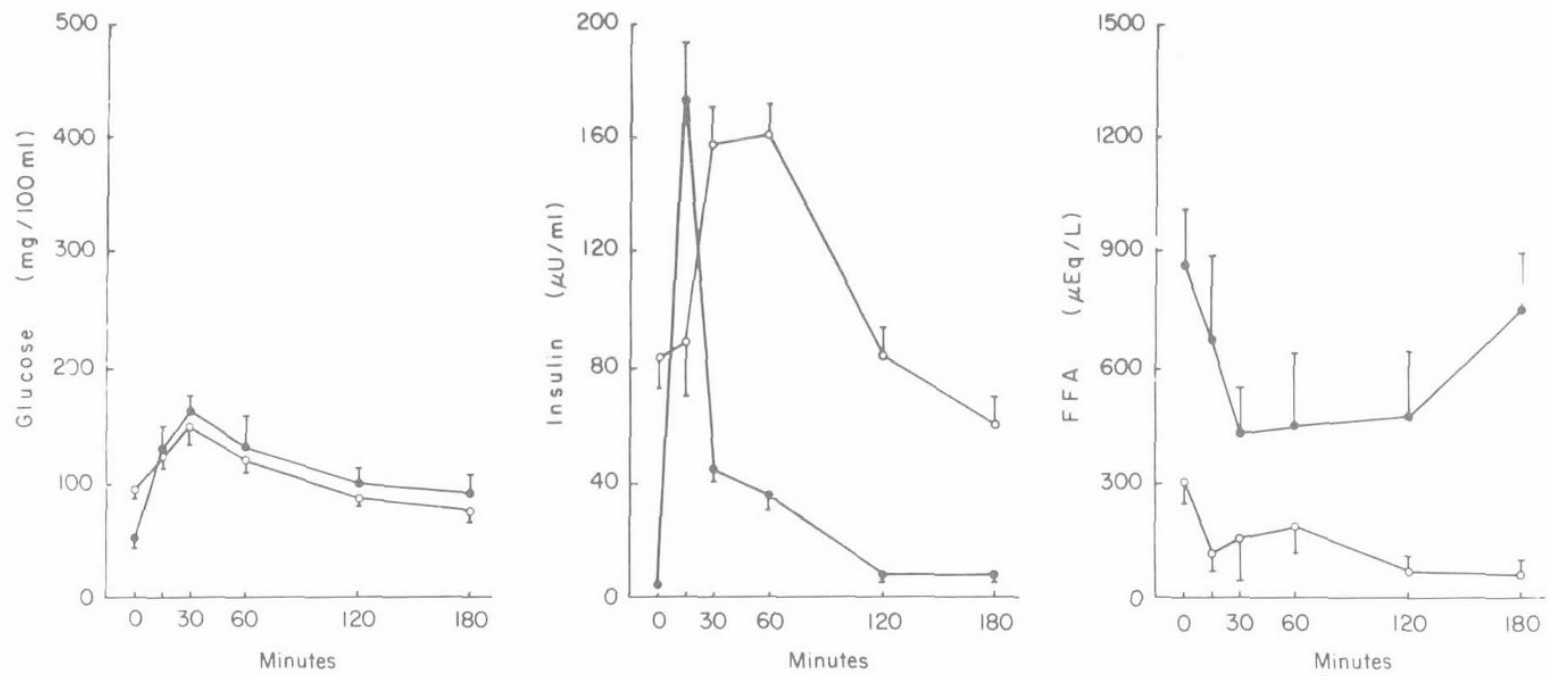

Fig. 1. Serum glucose, insulin and free fatty acids $(F F A)$ of dam and fetus after an oral glucose load in 21-day-old pregnant rats. $\bullet-\bullet$ : dam; $\circ \_$: fetus. Each point represents the average of eight determinations $\pm \mathrm{SE}$. 

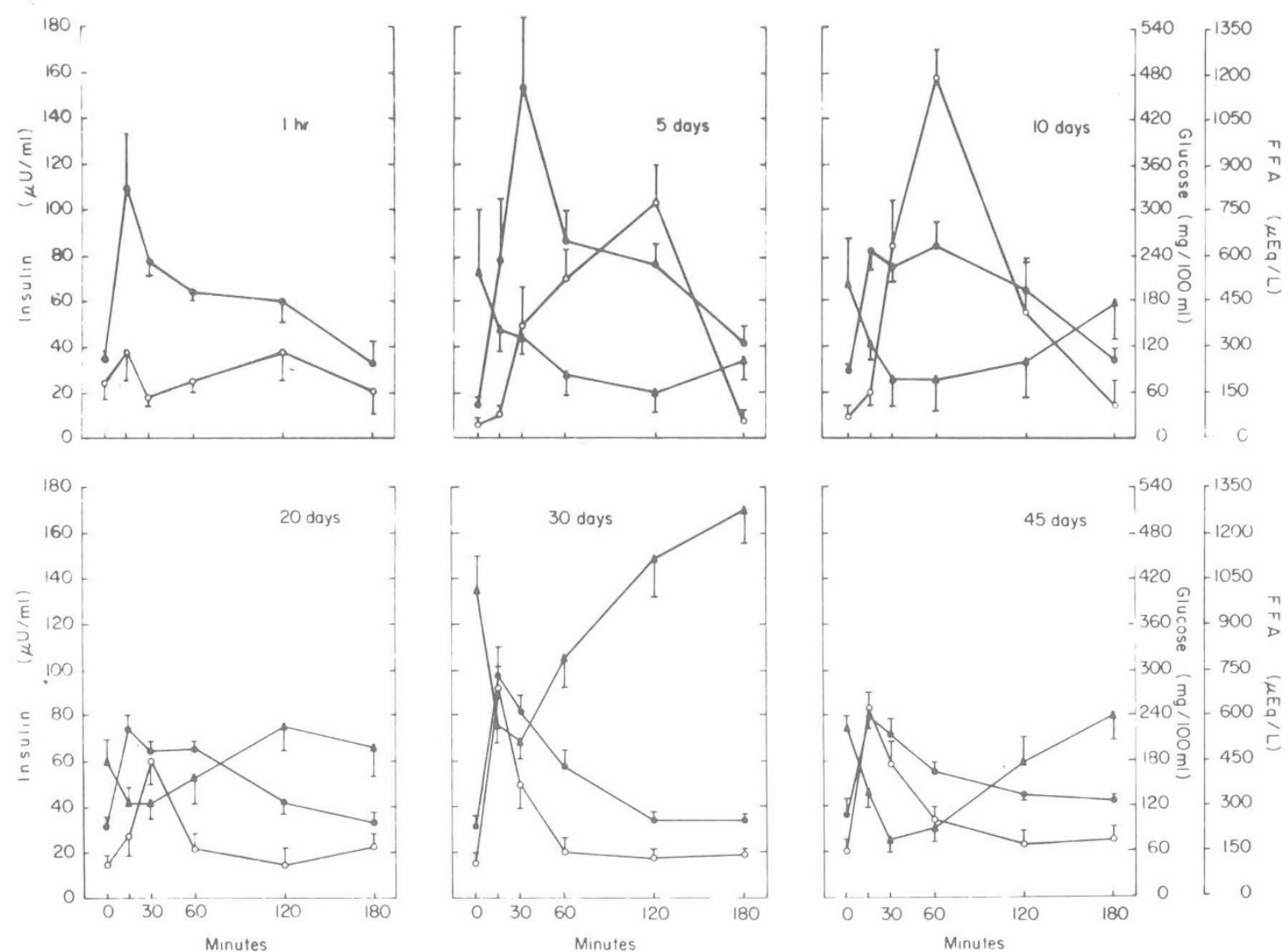

Fig. 2. Serum glucose, insulin, and free fatty acids $(F F A)$ after the oral administration of glucose to rats of different ages. $\bullet \longrightarrow \bullet$ : glucose; $\triangle \_$: insulin; $\triangle \_\triangle$ : FFA. Each point represents the average of 8 to 10 determinations \pm SE.
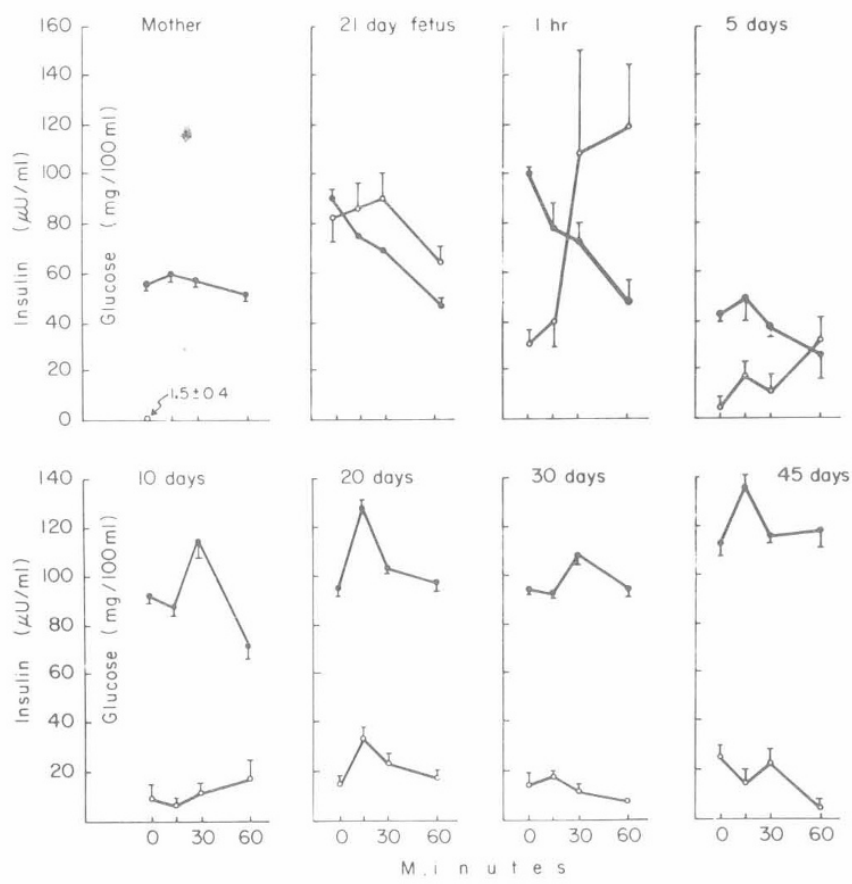

Fig. 3. Serum glucose, insulin, and free fatty acids after the oral administration of a mixture of 10 amino acids to rats of different ages. $\bullet$ : glucose; ○_ $\bigcirc$ : insulin. Each point represents the average of eight determinations \pm SE.

proinsulin increased relative to that of insulin, which became negligible (Fig. 6B). A more balanced distribution of label between the two peaks was noted when islets of older animals were used (Fig. 6C). The synthesis of proinsulin and of insulin by islets of fetal, nursing, and adult rats was greater when the

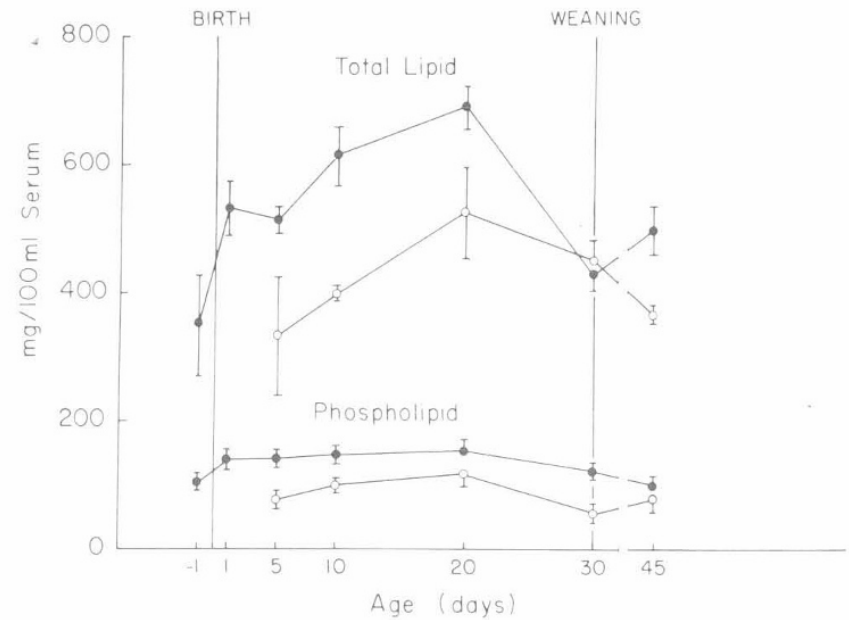

Fig. 4. Serum lipids of rats at different ages. $-\bullet$ : fed animals; ○_ O : after a 20-hr fast. Each point represents the average of three determinations $\pm \mathrm{SE}$.

concentration of glucose in the incubation medium was increased from 100 to $300 \mathrm{mg} / 100$ or when the incubation period was extended to $4 \mathrm{hr}$ (Figs. 7 and 8 ). The very small synthesis of insulin relative to proinsulin by islets of newborn rats can be seen again in Figure $8 B$.

Histologic Studies. Our results were similar to those reported by other authors $(30,41)$ and indicate that the proportion endocrine to exocrine pancreatic tissue was greater in fetal and newborn rats and decreased significantly and progressively in older animals (Fig. 9). These studies help document the observation that the pancreas of a neonatal and of a nursing rat yielded more islets than that of a 30- or 45-day-old animal. 

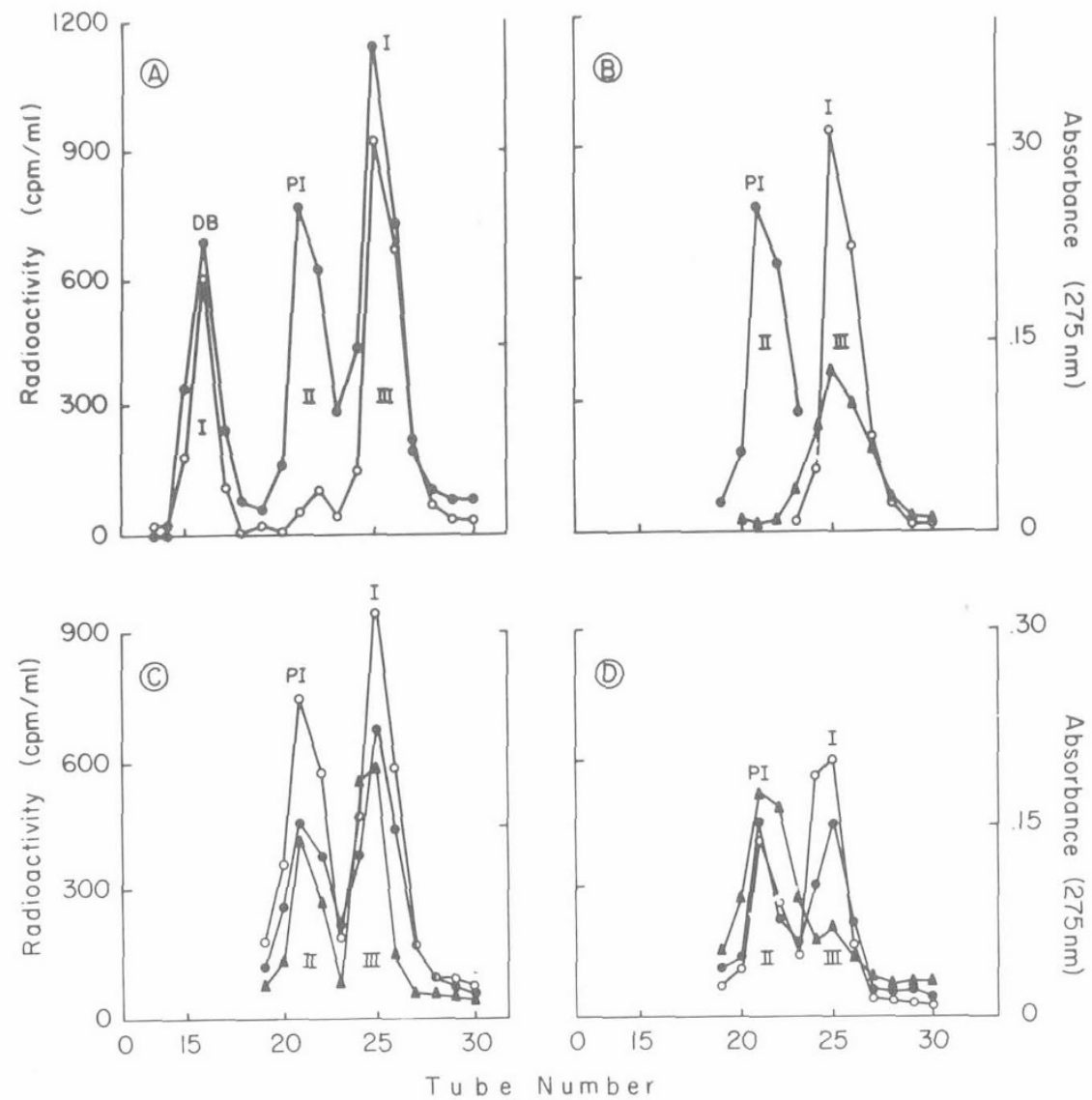

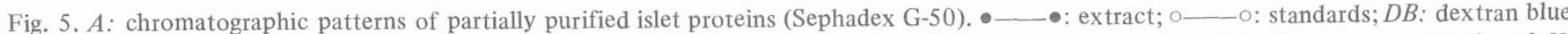
and albumin; PI: proinsulin; I: insulin. Glucose concentration in the medium: $300 \mathrm{mg} / 100 \mathrm{ml}$; incubation time: $4 \mathrm{hr}$. B: $\bullet-\bullet$, original peak II; $\triangle \_\triangle$ : peak II after treatment with trypsin; ○_— : insulin. C: effect of glucose concentration in the incubation medium. Peaks II and III obtained after $5 \mathrm{hr}$ of incubation. Glucose concentration: $\triangle \longrightarrow \triangle, 100 ; \bullet-\bullet, 200 ; \circ-\circ, 300 \mathrm{mg} / 100 \mathrm{ml}$. $D$ : effect of incubation time. Pattern obtained after $1 \mathrm{hr}, \triangle \longrightarrow \Delta ; 2 \mathrm{hr}, \bullet \longrightarrow$; or $3 \mathrm{hr}, \circ \longrightarrow$. Glucose concentration, $100 \mathrm{mg} / 100 \mathrm{ml}$.
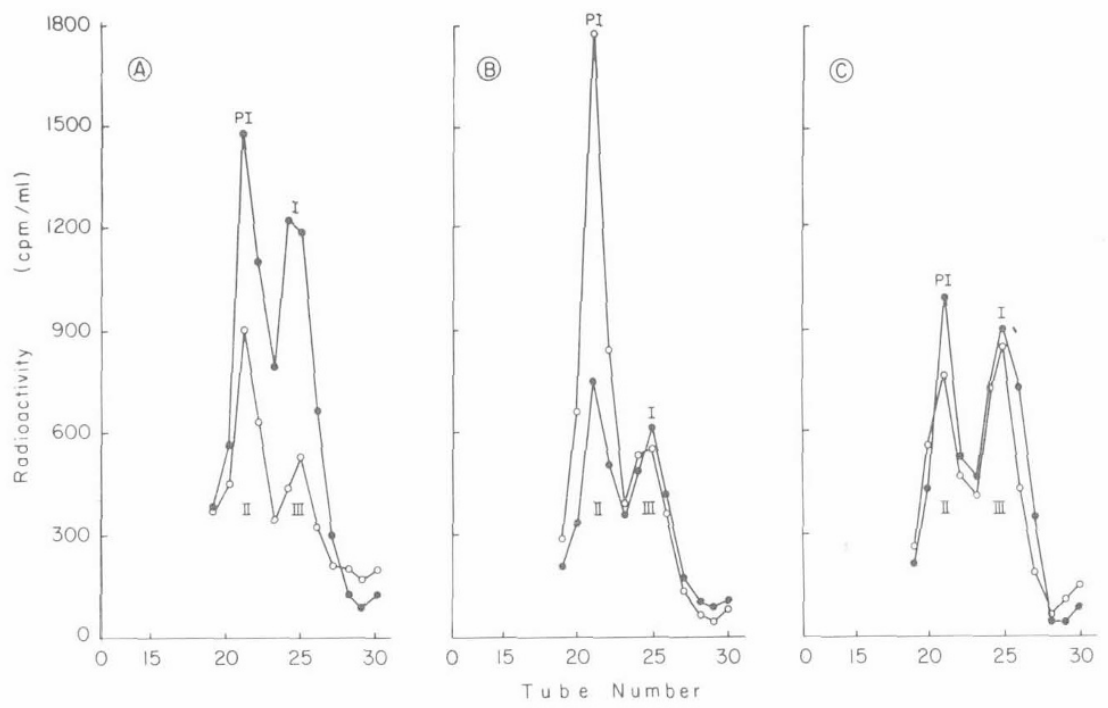

Fig. 6. Chromatographic patterns of partially purified islet proteins. Glucose concentration in the medium, $300 \mathrm{mg} / 100 \mathrm{ml}$. Incubation time, 4

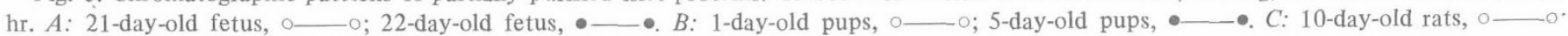
30-day-old rats, $\bullet$ PI: proinsulin; I: insulin.

\section{DISCUSSION}

Insulin has been found in the pancreas of the rat fetus as early as on the 11 th day of gestation (59). However, the full maturation of the hormonal secretory process appears to be delayed until after birth (2). The results in this paper and elsewhere $(14,33)$ indicate that even though the basal serum glucose and IRI levels of the 21-day-old fetuses were higher than those of their dam and responded more slowly to hyperglycemia, the fetal and maternal glucose tolerance were similar. We believe that the relative fasting hyperglycemia of the fetus may reflect the progressive increase of circulating glucose concentration which has been noted between the 19 th and 22 nd day of gestation and which, in association with other 

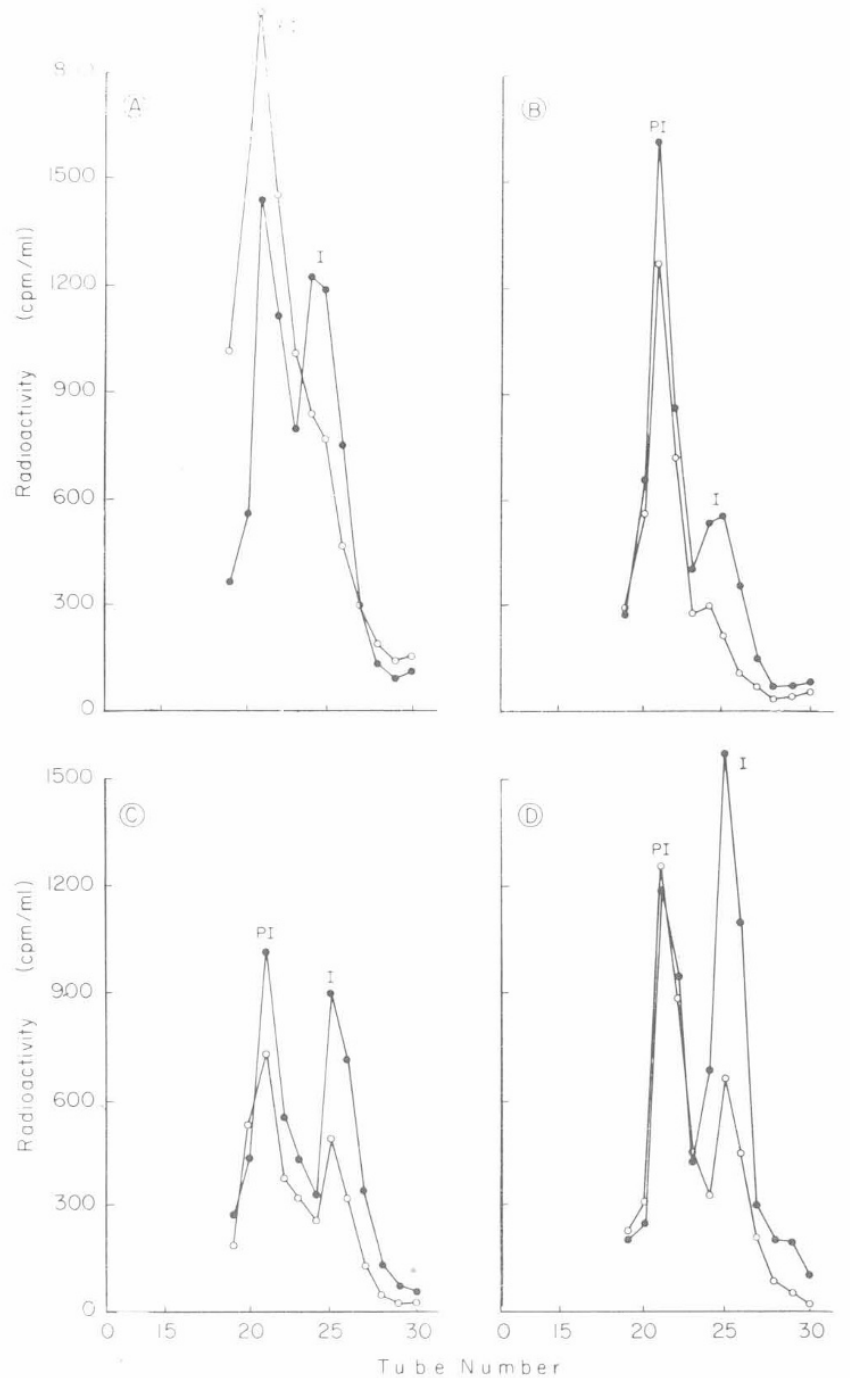

Fig. 7. Chromatographic patterns of partially purified islet proteins. Glucose concentration in the medium: $100 \mathrm{mg} / 100 \mathrm{ml}, \circ \longrightarrow \circ ; 300$ $\mathrm{mg} / 100 \mathrm{ml}$, $\longrightarrow$. Incubation time, $4 \mathrm{hr}$. $A$ : 5-day-old rats; $B$ : 30-day-old rats. $P I$ : proinsulin; $I$ : insulin.

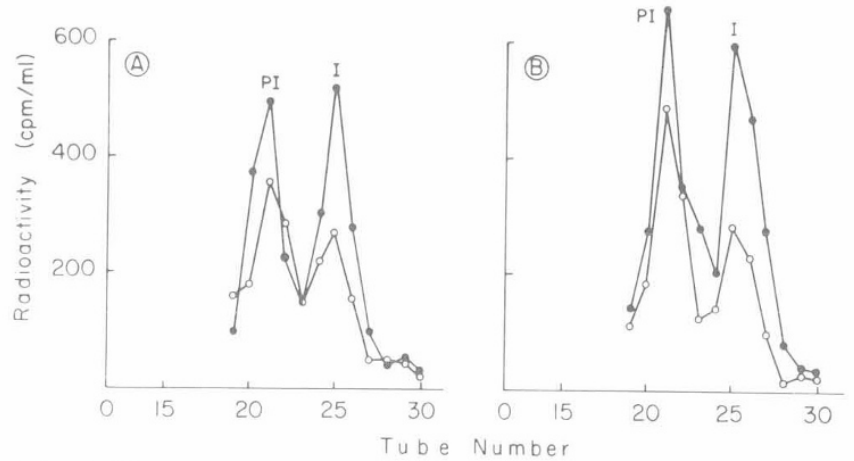

Fig. 8. Chromatographic patterns of partially purified islet proteins. Glucose concentration in the medium, $300 \mathrm{mg} / 100 \mathrm{ml}$. Incubation time, $2 \mathrm{hr}, \circ \longrightarrow$ ○; $4 \mathrm{hr}, \bullet \longrightarrow$. A: 22-day-old fetus; B: 1-day-old pups; $C$ : 30 -day-old rats; $D: 45$-day-old rats. $P I$ : proinsulin; $I$ : insulin.

factors, may promote the maturation of the B cell $(4,25)$. On the other hand, the similarity of the two glucose tolerance curves may be due to the permeability of the placenta to glucose and to its impermeability to insulin (34), which would allow the relatively large maternal glucose load to overpower any potential effect of the fetal insulin response. The decrease in maternal serum FFA concentration after glucose ingestion most likely is the result of the well known actions of glucose and insulin, whereas the high fetal metabolic rate, the relative impermeability of the placenta to fatty acids (67), and the absence of white adipose tissue (38) may be additional reasons for the low serum FFA values found in the fetus.

Immediately after birth, the situation undergoes a significant change destined to last about 3 weeks and characterized by a marked glucose intolerance and by an increase of serum lipids. During this period, the islets release relatively little insulin and, as noted also by other workers, the fasting serum IRI level is low $(2,13,14,26,30)$ and so is the insulinogenic response $(49,55,64)$.

These phenomena appear to be reflections of a change in the synthetic activity of the B cell, as indicated by the fact that, although the islets of fetal rats synthesized proinsulin and insulin actively, in the islets of 1-day-old pups, a relatively large leucine incorporation into the proinsulin molecule was accompanied by negligible insulin synthesis. This neonatal
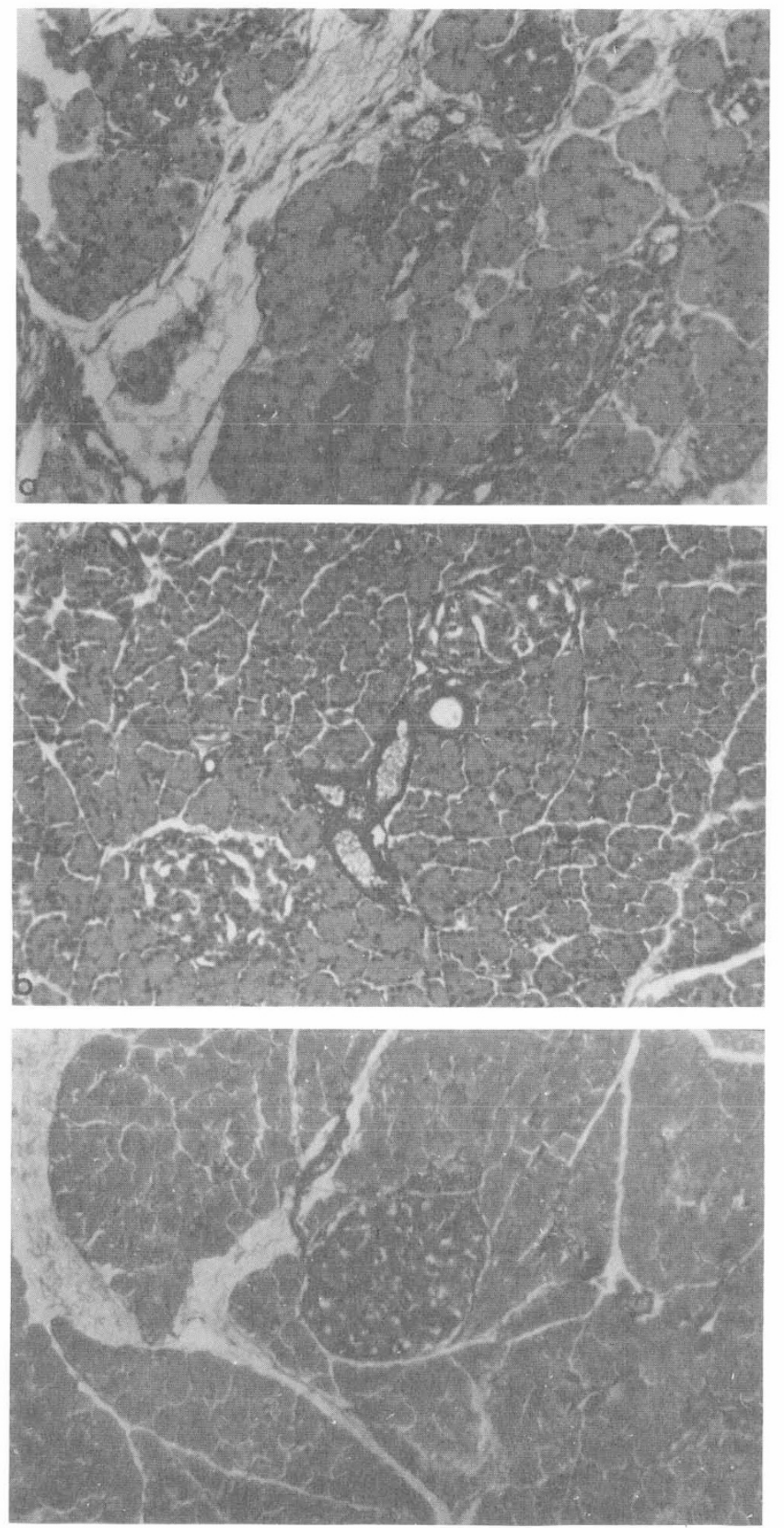

Fig. 9. Rat pancreas. $a$ : 21-day-old fetus; $b$ : 5-day-old rat; $c$ : 45-day-old rat. Phloxine-azure-hematoxylin (54). Microscope setting: $\times 100$. 
decrease of insulin synthesis confirms recent findings of Asplund (5), although this author found that the synthesis of proinsulin was also diminished. In older animals the conversion of proinsulin to insulin resumed and so did the ability of the B cell to release the hormone. However, the maturation of the mechanism for insulin release was slower than that for insulin synthesis, so that the total assayable insulin content of the islets was greater at the age of 5 and 10 days than at the age of 30 and 45 days. Thus, our results suggest that insular function and the ability to dispose of a glucose load do not reach full maturity until after the 3 rd week of life. Among the possible factors contributing to these perinatal changes are the maturation of the adenyl cyclase system and the stress of birth $(14,32)$. These two factors, in turn, may be related to the activity of the autonomic nervous structures surrounding the fetal rat islets $(57)$ or to the release catecholamines $(14,33)$ and, in this manner, may modulate insulin and glucagon secretion and stimulate glycogenolysis and lipolysis (4, 11, 12). Thus, the perinatal maturation of the insulin secretory system may be related to nutritional factors, for, just as the development of the fetal insulin secretory system is accelerated by the availability of glucose, so the carbohydrate intolerance of the young pup may be the result of the hyperlipidemia and hyperketonemia that follow the sudden change from fetal nutrition, based almost exclusively on maternal glucose (14) to the relatively high fat, low carbohydrate milk diet $(1,14,22)$. Indeed, in the adult $(9,10,52,68)$. as well as in the weaning (7, 8, $13,14,17,31,46,56,71,72)$ rat, a high fat diet increases serum lipids and decreases glucose tolerance, hepatic glucokinase activity, insulin secretion, and insulin sensitivity, whereas hyperlipemia and relative insulin resistance are characteristic of conditions as different as pregnancy, fasting, diabetes, and obesity $(29,43,62)$. Thus, the availability of lipids in the newborn rat in which gluconeogenesis is the major source of glucose, may have a glucose- and, hence, a protein-sparing effect. The manner in which these metabolic changes occur has not been defined. It may involve inhibition of glycolysis by fatty acids (60) or a decrease in the number of insulin receptors (47). As the rat pups grow to maturity, are weaned, and return to a high carbohydrate diet, their tolerance for glucose gradually improves. This is the time when glucokinase, an enzyme that is inducible by insulin (61), appears in their liver $(69,70)$.

Amino acids are transported across the placenta against a concentration gradient (67) and can reach high levels in the fetus (19). Thus, the failure of an amino acid mixture, given to the dam, to cause a significant insulinogenic response in her 21-day-old fetus, cannot be attributed to inadequate stimulation. Rather, the phenomenon, consistent with observations made in cultures of fetal pancreas (48) and in premature human infants (35), may indicate that the pancreatic B cells do not recognize amino acids. These would have to be converted to glucose, but in the rat, gluconeogenesis does not start until the suckling age (58). Finally, inasmuch as we administered glucose and amino acids orally, the secretion of intestinal hormones could have played a role in determining the insulinogenic response. Little is known about the ontogeny of these hormones, except that the first ingestion of food increases significantly the concentration of enteroglucagon in the serum of the neonate $(15,65)$.

The relatively high rate of biosynthesis, accompanied by a relatively low pancreatic insulin content and by relatively high levels of circulating hormone, characteristic of the rat fetus, are consistent with the observations of other workers $(5,13,63)$ and suggest that the insulin turnover is faster in the fetus than in the suckling animal. On the other hand, if one calculates the ratio of the amount of insulin secreted by pancreatic islets isolated from animals of different ages and incubated in buffer containing glucose at concentrations of 30 and $300 \mathrm{mg} / 100 \mathrm{ml}$, one observes (Table 1) a rather symmetrical developmental pattern which indicates that relatively more insulin is secreted at low glucose concentration at an age when glucose tolerance is impaired. We do not know a mechanism that would explain this phenonenon, but we wish to point out that a similar discrepancy exists between the concentration of glucose and the fetal secretion of glucagon $(15,23,51)$ and of growth hormone (20). This analysis of our results leads us to conclude that, in the rat, the process of insulin biosynthesis appears to develop before that of insulin release and that insular function and the ability to dispose of a glucose load do not reach full maturity until after the 3rd week of extrauterine life.

\section{SUMMARY}

We have studied the secretion of insulin by rat fetus in utero and by neonatal and young pups up to the age of 45 days. Using oral loads of glucose or amino acids, given either to the pregnant dam or to the young rats, we demonstrated that up to 10 days after birth, the insulinogenic response of the animals was delayed and their tolerance for glucose was depressed, in comparison with responses of older animals. In other experiments pancreatic islets were isolated by collagenase digestion and incubated in buffer containing glucose at 30 or $300 \mathrm{mg} / 100 \mathrm{ml}$. Although the islets of nursing animals contained the largest amount of insulin and responded well to glucose stimulation in vitro, the largest amount of insulin was released by islets of 30 - and 45 -day-old rats. Islets of fetal, nursing, and adult rats incorporated ${ }^{3} \mathrm{H}$-labeled leucine into proinsulin and insulin, especially when the concentration of glucose in the buffer was high. The conversion of proinsulin to insulin was minimal in the 1-day-old rat and increased with the age of the animal. Although the mechanism for the synthesis of insulin appears to be effective before birth, the mechanism for its release does not reach full maturity until after the 3rd

Table 1. Insulin content and insulin by islets of neonatal, weaned, and young adult rats ${ }^{1}$

Insulin secretion, $\mu \mathrm{U} / 10$ islets $/ 2 \mathrm{hr}$

\begin{tabular}{|c|c|c|c|c|c|c|}
\hline $\begin{array}{l}\text { Rat age, } \\
\text { days }\end{array}$ & $\begin{array}{l}\text { Glucose conc. A, } \\
30 \mathrm{mg} / 100 \mathrm{ml}\end{array}$ & & $\begin{array}{l}\text { Glucose conc. B, } \\
300 \mathrm{mg} / 100 \mathrm{ml}\end{array}$ & Ratio A/B & Insulin content, $\mu \mathrm{U} / 10$ islets & $\begin{array}{c}\text { Secretion/content }{ }^{2} \\
\times 100\end{array}$ \\
\hline 1 & $133 \pm 27(4)$ & & $511 \pm 43(9)$ & 0.26 & & \\
\hline 5 & $311 \pm 91(7)$ & & $585 \pm 144(8)$ & 0.53 & $20,618 \pm 2514(10)\}$ & 2.8 \\
\hline 10 & $1,003 \pm 140(6)$ & & $1,456 \pm 206(7)$ & 0.68 & $18,481 \pm 1405(17)\}$ & 7.8 \\
\hline $\begin{array}{l}30 \\
45\end{array}$ & $\begin{array}{l}581 \pm 41(6) \\
258 \pm 46(6)\end{array}$ & $\begin{array}{l}\leftarrow P<0.001 \rightarrow \\
\leftarrow P<0.001 \rightarrow\end{array}$ & $\begin{array}{l}1,433 \pm 190(8) \\
1,690 \pm 218(8)\end{array}$ & $\begin{array}{l}0.4 \mathrm{C} \\
0.15\end{array}$ & $\left.\begin{array}{r}8,038 \pm 1647 \quad(4) \\
11,459 \pm 1308(12)\end{array}\right\}$ & $\begin{array}{l}17.8 \\
14.7\end{array}$ \\
\hline
\end{tabular}

${ }^{1}$ Average \pm SE. Number of experiments in parentheses.

${ }^{2}$ Glucose concentration $300 \mathrm{mg} / 100 \mathrm{ml}$. 
week of extrauterine life. This relatively slow development helps provide a hormonal environment conducive to gluconeogenesis and to glucose economy at an age when the only source of exogenous carbohydrate is milk. Full maturation of the insulin secretory machanism and a glucose tolerance similar to that of the adult rat was reached only after weaning when the animals were switched from a high fat, high protein mlik diet, to a high carbohydrate commercial rat food.

\section{REFERENCES AND NOTES}

1. Aranda, A., Blázquez, E., and Herrera, E.: Liver components, blood glucose and ketone bodies in fed and starved suckling rats. Hormone Metab. Res., 5: 350 (1973).

2. Asplud, K.: The effect of glucose on the insulin secretion in foetal and newborn rats. In: S. Falkmer, B. Hellman, and I.-B. Täljedal: The Structure and Metabolism of the Pancreatic Islets, p. 477 (Pergamon Press, London, 1970).

3. Asplund, K.: Effects of postnatal feeding on the functional maturation of pancreatic islet B cells of neonatal rats. Diabetologia, 8: 153 (1972).

4. Asplund, K.: Insulin biosynthesis and release in the foetus and newborn. An experimental study in the rat: A Dissertation. Acta Univ. Uppsala no. 145 (Almqvist and Wiksell, Stockholm, 1972).

5. Asplund, K.: Effects of glucose on insulin biosynthesis in foetal and newborn rats. Hormone Metabol. Res., 5: 410 (1973).

6. Baginski, E. S., Foà, P. P., and Zak, B.: Determination of phosphate and phosphomonoesterases in biologic materials. Amer. J. Med. Technol., 35: 475 (1969).

7. Ballard, F. J.: Gluconeogenesis and the regulation of blood glucose in the neonate. In: R. R. Rodriguez and J. Vallance-Owen: Diabetes, p. 592 (Excerpta Medica Foundation, ICS No. 231, Amsterdam, 1971)

8. Ballard, F. J., and Oliver, I. T.: Appearance of fructose 1.6-diphosphatase in postnatal rat liver. Nature, 195: 498 (1962).

9. Blázquez, E., Castro, M., and Herrera, E.: Effect of a high-fat diet on pancreatic insulin release, glucose tolerance and hepatic gluconeogenesis in rats. Rev. Espanol. Fisiol., 27: 297 (1971).

10. Blázquez, E., and Lopez Quijada, C.: The effect of a high-fat diet on glucose, insulin sensitivity and plasma insulin in rats. $\mathrm{J}$. Endocrinol., 42: 489 (1968).

11. Blázquez, E., and Lopez Quijada, C.: The effect of a high carbohydrate diet on glucose, insulin sensitivity and plasma insulin in rats. J. Endocrinol., 44: 107 (1969).

12. Blázquez, E., and Lapez Quijada, C.: The effect of a high protein diet on glucose, insulin sensitivity and plasma insulin in rats. J. Endocrinol., 46: 445 (1970).

13. Blázquez, E., Montoya, E., and Lopez Quijada, C.: Relationship between insulin concentrations in plasma and pancreas of foetal and weanling rats. J. Endocrinol., 48: 553 (1970).

14. Blázquez, E., Sugase, T., Blázquez, M., and Foà, P. P.: The ontogeny of metabolic regulation in. the rat, with special reference to the development of insular function. Acta Diabetol. Latina, 9 (suppl. 1): 13 (1972).

15. Blázquez, E., Sugase, T., Blázquez, M., and Foà P. P.: Neonatal changes in the concentration of rat liver cyclic AMP and of serum glucose, free fatty acids, insulin pancreatic and total glucagon in man and in the rat. J. Lab. Clin. Med., 83: 957 (1974).

16. Bray, G. A.: A simple efficient liquid scintillator for counting aqueous solutions in a liquid scintillation counter. Anal Biochem., 1: 279 (1960).

17. Cake, M. H., and Oliver, I. T.: The activation of phosphorylase in neonatal rat liver. Eur. J. Biochem., 11: 57.

18. Chernick, S., and Novak, M.: Effect of insulin on FFA mobilization and ketosis in fasting pregnant rats. Diabetes, 19: 563 (1970).

19. Christensen, H. N., and Streicher, J. A.: Association between rapid growth and elevated cell concentrations of amino acids in fetal tissues. J. Biol. Chem., 175: 95 (1948).

20. Cornblath, M., Parker, M. L., Reisner, S. H., Forbes, A. E., and Daughaday, W. H.: Secretion and metabolism of growth hormone in premature and full-term infants. J. Clin. Endocrinol. Metab., 25: 209 (1965).

21. Davoren, P. R.: The isolation of insulin from a single cat pancreas. Biochim. Biophys. Acta, 63: 150 (1962).

22. Dymsza, H. A., Czajka, D. M., and Miller, S. A.: Influence of artificial diet on weight gain and body composition of the neonatal rat. J. Nutr., 84: 100 (1964).

23. Edwards, J. C. Asplund, K., and Lundqvist, C.: Glucagon release from the pancreas of the newborn rat. J. Endocrinol., 54: 493 (1972).

24. Everett, J.: The mammalian female reproductive cycle and its controlling mechanisms. In: W. C. Young: Sex and Internal Secretions, Vol. 1, p. 497 (The Williams and Wilkins Co., Baltimore, 1961).

25. Farquhar, J. W.: Maternal hyperglycaemia and fetal hyperin- sulinism in diabetic pregnancy. Postgrad. Med. J., 38: 612 (1962).

26. Felix, J. M., Sutter, M. T., Sutter, B. J., and Jacquot, R.: Circulating insulin and tissular reactivity to insulin in the rat during the perinatal period. Hormone Metab. Res., 3: 71 (1971).

27. Floyd, J. C., Jr., Fajans, S. S., Conn, J. W., Knopf, R. F., and Rull, J.: Stimulation of insulin secretion by amino acids. J. Clin, Invest., 45: 1487 (1966).

28. Folch, J., Lees, M., and Stanley, G. H. S.: A simple method for the isolation and purification of total lipid from animal tissues. J. Biol. Chem., 226: 497 (1957).

29. Friedman, B., Goodman, E. H., Jr., and Weinhouse, S.: Dietary and hormonal effects on gluconeogenesis in the rat. J. Biol. Chem., 240: 3729 (1965).

30. Frye, B. E.: The differentiation of the endocrine pancreas in fetuses of alloxan diabetic and insulin-treated rats. J. Morphol., 101: 325 (1957).

31. Girard, J. R., Bal, D., and Assan, R.: Glucagon secretion during the early postnatal period in the rat. Hormone Metab. Res., 4: 168 (1972).

32. Girard, J. R., Cuendet, G. S., Marliss, E. B., Kervran, A., Rieutort, M., and Assan, R.: Fuels, hormones, and liver metabolism at term and during the early postnatal period in the rat. J. Clin. Invest., 52: 3190 (1973).

33. Girard, J. R., Kervran, A., Souffet, E., and Assan, R.: Factors affecting the secretion of insulin and glucagon by the rat fetus. Diabetes, 23: 310 (1974).

34. Goodner, C. J., and Freinkel, N.: Carbohydrate metabolism in pregnancy. IV. Studies on the permeability of the rat placenta to ${ }^{1}{ }^{1} \mathrm{I}$-insulin. Diabetes, 10: 383 (1961).

35. Grasso, S., Messina, A., Saporito, N., and Reitano, G.: Seruminsulin response to glucose and amino acids in the premature infant. Lancet, $i i: 755$ (1968).

36. Grillo, T. A. I.: The occurrence of insulin in the pancreas of fetuses of some rodents. J. Endocrinol., 31: 67 (1964).

37. Grodsky, G. M.: Insulin and the pancreas. Vitamins Hormones, 28: 37 (1970).

38. Hahn, P.: Response of brown and white adipose tissue to lipolytic agents in the rat during development. Pediat. Res., 5: 126 (1971).

39. Hales, C. N., and Randle, P. J.: Immunoassay of insulin with insulin-antibody precipitate. Biochem. J., 88: 137 (1963).

40. Hanks, J. H., and Wallace, R. E.: Relation of oxygen and temperature in the preservation of tissues by refrigeration. Proc. Soc. Exp. Biol. Med., 71: 196 (1949).

41. Hard, W. L.: The origin and differentiation of the alpha and beta cells in the pancreatic islets of the rat. Amer. J. Anat., 75: 369 (1944).

42. Hegre, O. D., McEvoy, R. C., Bachelder, V., and Lazarow, A.: Fetal rat pancreas: Differentiation of the islet cell component in vivo and in vitro. Diabetes, 22: 577 (1973).

43. Herrera, E., Knopp, R. H., and Freinkel, N.: Carbohydrate metabolism in pregnancy. VI. Plasma fuels, insulin, liver composition, gluconeogenesis, and nitrogen metabolism during late gestation in the fed and fasted rat. J. Clin. Invest., 48: 2260 (1969).

44. Hugget, A. S., and Nixon, D. A.: Use of glucose oxidase, peroxidase and $o$-dianisidine in determination of blood and urinary glucose. Lancet, ii: 368 (1957).

45. Hunter, W. M., and Greenwood, F. C.: Preparation of iodine-131 labelled human growth hormone of high specific activity. Nature, 194: 495 (1962).

46. Jost, A., and Picon, L.: Hormonal control of fetal development and metabolism. Advan. Metab. Disord., 4: 123 (1970).

47. Kahn, C. R., Neville, D. M., Jr., and Roth, J.: Insulin-receptor interaction in the obese-hyperglycemic mouse: A model of insulin resistance. J. Biol, Chem., 248: 224 (1973).

48. Lambert, A. E., Jeanrenaud, B., Junod, A., and Renold, A. E.: Organ culture of fetal rat pancreas. II. Insulin release induced by amino and organic acids, by hormonal peptides, by cationic alterations of the medium and other agents. Biochim. Biophys. Acta, 184: 540 (1969).

49. Lavine, R. L., Chick, W. L., Like, A. A., and Makdisi, T. W. Glucose tolerance and insulin secretion in neonatal and adult mice. Diabetes, 20: 134 (1971).

50. Lernmark, §., and Wenngren, B. I.: Insulin and glucagon itlease from the isolated pancreas of foetal and newborn mice. J. Embryol. Exp. Morhpol., 28: 607 (1972).

51. Luyckx, A. S., Massi-Benedetti, F., Falorni, A., and Lefèbvre, P. J. Presence of pancreatic glucagon in the portal plasma of human neonates. Difference in the insulin and glucagon responses to glucose between normal infants and infants from diabetic mothers. Diabetologia, 8: 296 (1972).

52. Malaisse, W. J., Lemonnier, D., Malaisse-Lagae, F, and Mandelbaum, I. M.: Secretion of and sensitivity to insulin in obese rats fed a high-fat diet. Hormone Metabol. Res., 1: 9 (1969).

53. Malaisse, W., Malaisse-Lagae, F., and Wright, P. H.: A new method for the measurement in vitro of pancreatic insulin secretion. 
Endocrinology, 80: 99 (1967).

54. Maldonado, R., and San José, H.: A phloxine-azure-hematoxylin sequence for differential staining of cells in pancreatic islets. Stain Technol., 42: 11 (1967).

55. Mintz, D. H., Chez, R. A., and Horger, E. O. III: Fetal insulin and growth hormone metabolism in the subhuman primate. J. Clin. Invest., 48: 176 (1969).

56. Okuno, G., Price, S., Grillo, T. A. I., and Foà, P. P.: Development of phosphorylase and phosphorylase-activating (glucagon-like) substances in the rat embryo. Gen. Comp. Endocrinol., 4: 446 (1964).

57. Perrier, H.: Evolution de l'ultrastructure du pancréas chez le foetus de rat. Diabetologia, 6: 605 (1970).

58. Philippidis, H., and Ballard, F. J.: The development of gluconeogenesis in rat liver. Biochem. J., 113: 651 (1969).

59. Pictet, R., Clark, W. R., Rutter, W. J., and Williams, R. H.: Embryonic development of the endocrine pancreas. II. Ultrastructural analysis. Diabetes, 18 (suppl. 1): 321 (1969).

60. Randle, P. J., Garland, P. B., Newsholme, E. A., and Hales, C. N.: The glucose fatty acid cycle in obesity and maturity onset diabetes mellitus. Ann. N. Y. Acad. Sci., 131: 324 (1965).

61. Salas, M., Viñuela, E., and Sols, A.: Insulin-dependent synthesis of liver glucokinase in the rat. J, Biol. Chem., 238: 3535 (1963).

62. Sandler, R., Herrera, E., and Freinkel, N.: Glucose overproduction in obese-hyperglycemic mice. Clin. Res., 16: 351 (1968).

63. Sodoyez-Goffaux, F., Sodoyez, J.-C., and Foà, P. P.: Effects of gestational age, birth and feeding on the insulinogenic response to glucose and tolbutamide by fetal and newborn rat pancreas. Diabetes, 20: 586 (1971).

64. Spellacy, W. N., Gall, S. A., and Carlson, K. L.: Carbohydrate metabolism of the normal term newborn: Plasma insulin and blood glucose levels during an intravenous glucose tolerance test. Obstet. Gynecol., 30: 580 (1967).

65. Sperling, M.A., DeLamater, P. V., Phelps, D., Fiser, R. H., Oh, W., and Fisher, D. A.: Spontaneous and amino acid-stimulated glucagon secretion in the immediate postnatal period: Relation to glucose and insulin. J. Clin. Invest., 53: 1159 (1974).

66. Steiner, D. F., and Oyer, P. E.: The biosynthesis of insulin and a probable precursor of insulin by a human islet cell adenoma. Proc. Nat. Acad. Sci. U.S. A., 57: 473 (1967).

67. Szabo, A. J., and Grimaldi, R. D.: The metabolism of the placenta.
Advan, Metab, Dis., 4: 185 (1970).

68. Vaughan, D. A., Hannon, J. P., and Vaughan, L. N.: Effects of diet on selected glycolytic enzymes of the rat. Amer. J. Physiol., 199: 1041 (1960).

69. Walker, D. G.: On the presence of two soluble glucose-phosphorylating enzymes in liver and the development of one of these after birth. Biochim. Biophys. Acta, 77: 209 (1963).

70. Walker, D. G., and Holland, G.: The development of hepatic glucokinase in the neonatal rat. Biochem. J., 97: 845 (1965).

71. Yeung, D., and Oliver, I. T.: Induction of phosphopyruvate carboxylase in neonatal rat liver by adenosine 3',5'-cyclic monophosphate. Biochemistry, 7: 3231 (1968).

72. Yeung, D., Stanley, R. S., and Oliver, I. T.: Development of gluconeogenesis in neonatal rat liver. Effect of triamcinolone. Biochem. J., 105: 1219 (1967).

73. Gift of Dr. J. Schlichtkrull, Novo Research Institute, Copenhagen, Denmark.

74. Nutritional Biochemical Corporation, Cleveland, Ohio.

75. New England Nuclear, Boston, Mass.

76. Gift of Dr. Mary A. Root, The Lilly Research Laboratories, Indianapolis, Ind.

77. Sigma Chemical Company, St. Louis, Mo.

78. Gift of Dr. Peter H. Wright, Indiana University Medical Center, School of Medicine, Indianapolis, Ind.

79. Prepared by Dr. J. C. Dunbar in our laboratory.

80. This study was supported in part by Grant no. AM06034 from the National Institute of Arthritis and Metabolic Diseases, United States Public Health Service, and by a grant from the Michigan Diabetes Association.

81. Dr. E. Blázquez is a fellow of the Fundacion Juan March, Madrid, Spain and a Trainee, Diabetes Training Program no. AM05474, National Institute of Arthrit is and Metabolic Diseases, United States Public Health Service.

82. Dr. L. A. Lipshaw is a trainee, Diabetes Training Program no. AM05474, National Institute of Arthritis and Metabolic Diseases, United States Public Health Service.

83. Requests for reprints should be addressed to: P. P. Faà, M.D., Department of Research, Sinai Hospital of Detroit, 6767 W. Outer Dr., Detroit, Mich. 48235 (USA)

84. Accepted for publication July 26, 1974. 